\title{
Current Surgical Management of Rectal Cancer
}

\author{
Masato Kusunoki Yasuhiro Inoue \\ Department of Gastrointestinal and Pediatric Surgery, Division of Reparative Medicine, Institute of Life Sciences, \\ Mie University Graduate School of Medicine, Mie, Japan
}

\section{Key Words}

Lymph node dissection, lateral $\cdot$ Mesorectal excision, total Rectal cancer

\begin{abstract}
The management of rectal cancer has undergone significant evolution over the past decade with improvements in both surgical technique and adjuvant therapies. The progression of surgical management has been of particular interest, as surgery is the only potentially curative treatment. The major goals of surgery are to optimize oncologic outcome and maintain anorectal and genitourinary function. There are presently two approaches to rectal cancer surgery: total mesorectal excision (TME), which is the gold standard in the Western world, and lateral lymph node dissection, which was originally developed in Japan. Although the results of lateral lymph node dissection are similar to TME with prior radiotherapy, low positive lateral lymph node yields, questionable prognostic significance, and high morbidity are the main drawbacks of this procedure. Despite the current quality of these surgical procedures, locoregional treatment is limited as advanced primary rectal cancer may be associated with systemic spread of disease. Adjuvant therapy therefore plays a key role in obtaining further improvement in survival. In this article, evidence for the use and benefits of lateral lymph node dissection surgery for rectal cancer patients in Japan is reviewed, and its application in association with TME and other modalities considered.
\end{abstract}

Copyright $\odot 2007$ S. Karger AG, Basel

\section{KARGER}

Fax +41613061234 E-Mail karger@karger.ch www.karger.com (c) 2007 S. Karger AG, Basel

0253-4886/07/0242-0115\$23.50/0

Accessible online at:

www.karger.com/dsu

\section{Introduction}

Treatment of rectal cancer has improved over the past decade with regard to both surgical techniques and adjuvant therapies. These advances have markedly reduced the incidence of recurrent disease while offering sphincter preservation to more patients with lower rectal cancer. Historically, using traditional operative techniques without adjuvant therapy, the outcome was poor and carried with it significant morbidity $[1,2]$. Therefore, (neo)adjuvant radiotherapy with or without chemotherapy has been used widely in an attempt to improve long-term outcome for rectal cancer in the Western world. However, surgery is the only potentially curative treatment modality for rectal cancer. In addition, as the main goals of surgery for rectal cancer are to optimize oncologic outcome and maintain anorectal and genitourinary function, the progression of surgical management has been of major interest. The most important advance in operative technique was the advent of total mesorectal excision (TME) proposed by Heald et al. [3] in 1982 as the standard surgical method to achieve good control and to preserve autonomic nerve function [4]. This has been the most important breakthrough in the management of rectal cancer to date.

To improve local control and survival lateral lymph node dissection has been used as a standard procedure for lower rectal cancer in Japan since the late 1970s, whereas in the Western world it has not been frequently

Masato Kusunoki, Department of Gastrointestinal and Pediatric Surgery

Division of Reparative Medicine, Institute of Life Sciences

Mie University Graduate School of Medicine, 2-174 Edobashi, Tsu

Mie 514-8507 (Japan)

Tel. +81 59231 5294, Fax +81 59232 6968, E-Mail kusunoki@clin.medic.mie-u.ac.jp 
used. Although the results of lateral lymph node dissection are similar to TME with prior radiotherapy, low positive lateral lymph node yields, questionable prognostic significance, and high morbidity (urinary and sexual dysfunction) are the main reasons against the use of this procedure. Recently, the use of preoperative radiotherapy for rectal cancer has also gradually increased in Japan. Therefore, decisions regarding the optimal surgical treatment for patients with rectal cancer have become more complex, especially with regard to surgical techniques such as lateral lymph node dissection with nerve-sparing and TME.

This article reviews the surgical management of rectal cancer in Japan and discusses major surgical considerations including lateral lymph node dissection and TME. The use of adjuvant therapy such as radiation therapy and chemotherapy in Japan are also reviewed.

\section{Surgical Technique}

Rationale of Surgical Treatment and Its Relationship to the Anatomy of Rectal Cancer Spread

In the early 20th century, Miles [5] revealed for the first time that lymphatic spread from rectal cancer occurred in 3 directions - upward, laterally, and downward. He emphasized the importance of including the surrounding regional lymph nodes with complete excision of the rectum and anus, and thus abdominoperineal rectal resection was born. Since then, an understanding of the importance of adequate lymph node dissection for both local recurrence and prognosis has become fundamental to the surgical approach to rectal cancer. With experience, it was recognized that although Miles' concept of the upward zone of lymphatic spread was correct, he had overestimated the incidence of distal and lateral lymphatic spread. In addition, improvement in stapling technology over the past 20 years has led to a dramatic increase in the number of curative sphincter-saving operations. The historical shift from radical abdominoperineal resection for rectal cancer to the use of sphinctersaving techniques has resulted primarily from a better understanding of what constitutes an adequate distal resection margin. In the 1980s, Williams et al. [6] and Pollett and Nicholls [7] proposed that perhaps even a $2-\mathrm{cm}$ distal resection margin was justifiable. However, recent studies indicate that the main reason for local recurrence is lateral spread rather than a positive resection margin $[3,8,9]$. Therefore, the recent emphasis of rectal cancer surgery has been on preservation of function, with dis- section in appropriate anatomical planes. In 1982, Heald et al. [3] emphasized the importance of recognizing the 'holy plane', in which the surgeon's dissection will encompass the malignancy and yet preserve autonomic neural function. TME was defined as complete excision of the visceral mesorectal tissue to the level of the levators [10]. The use of TME has undoubtedly improved the treatment of patients with rectal cancer in Europe and the United States.

Meanwhile, a different technique for the treatment of rectal cancer was developed in Japan. For rectal cancers, lymphatic spread occurs not only upward to the mesenteric nodes along the superior rectal and inferior mesenteric vessels, but also laterally to the hypogastric, obturator and presacral lymph nodes along the middle rectal, sacral and iliac vessels. Japanese surgeons have reported that the presence of lateral lymph node metastases along the iliac vessels is an important factor for local recurrence in patients with advanced low rectal cancer. Because lateral lymph nodes are not removed by dissection along the 'holy plane', patients with lateral node metastases have an increased risk of local recurrence when treated with TME alone.

\section{Lateral Lymph Node Dissection}

Incidence of Metastases, and Prognostic Significance

The reported incidence of lateral lymph node metastases ranges between 8.6 and $17.3 \%$ of patients with rectal cancer [11-18]. The local recurrence rate is high and survival rate is poor in patients who have positive lateral lymph nodes, even when compared with patients who have positive mesorectal lymph nodes [19]. In a retrospective analysis of 764 rectal cancer patients, Takahashi et al. [15] examined lateral lymphatic drainage anatomically and demonstrated that 66 patients had lateral lymph node metastases, which constituted $8.6 \%$ of all the cases and $16.4 \%$ of low-lying cases. As all of those patients underwent lateral lymph node dissection, resulting in a 5year survival rate of $75 \%$, the authors concluded that lateral lymphatic flow from low-lying rectal cancer passes outside the boundaries of TME but within the range of curative surgery by extended lateral lymph node dissection [15]. Several retrospective studies have shown a prognostic significance of lateral lymphatic spread in rectal cancer and an improved survival rate after resection with extended lateral lymph node dissection compared to conventional resection without lateral lymph node dissection $[14,15,17,20]$ (table 1$)$. 
Table 1. Oncologic outcome for potentially curative radical rectal resection of rectal cancer according to the principles of lateral lymph node dissection

\begin{tabular}{|c|c|c|c|c|c|}
\hline Reference & Year & Patients & Stage & Local recurrence & 5-Year survival \\
\hline Moriya et al. [14] & 1997 & 448 & $\begin{array}{l}\text { I, } 88 \\
\text { II, } 142 \\
\text { III, } 218\end{array}$ & $\begin{array}{l}\text { I, } 3.4 \% \\
\text { II, } 2.8 \% \\
\text { III, } 16.1 \% \\
\text { (all } 9.4 \% \text { ) }\end{array}$ & $\begin{array}{l}\text { Dukes C, } 55 \% \\
\text { Lateral node involvement, } 43 \%\end{array}$ \\
\hline Mori et al. [20] & 1998 & 157 & II, 157 & $7.40 \%$ & $\begin{array}{l}\text { Lateral node involvement } \\
32.1 \%(1975-1989) \\
43.3 \%(1988-1996)\end{array}$ \\
\hline Takahashi et al. [15] & 2000 & 764 & $\begin{array}{l}\text { I, II, } 425 \\
\text { III, } 339\end{array}$ & $\begin{array}{l}\text { I, II, } 1.9 \% \\
\text { III, } 15.3 \% \\
\text { (all } 7.8 \%)\end{array}$ & Lateral node involvement, $42.4 \%$ \\
\hline Morita et al. [17] & 2003 & 212 & - & all $6.3 \%$ & Lateral node involvement, $47 \%$ \\
\hline
\end{tabular}

\section{Autonomic Nerve Preservation}

Extended dissection has occasionally impaired urinary and male sexual function, resulting in poor postoperative quality of life (QOL), as the pelvic autonomic nervous system was often sacrificed during lateral lymph node dissection [21-23]. To address this problem, several reports from Japanese surgeons have demonstrated various pelvic autonomic nerve preservation (ANP) procedures with lateral lymph node dissection which resulted in improved urinary and sexual function compared to previous results [20, 24, 25]. Mori et al. [20] combined ANP resection with lateral lymph node dissection in patients with advanced lower rectal cancer. In cases of ANP with lateral dissection the local recurrence rate was $4.8 \%$ overall and $7.4 \%$ in the Dukes $C$ group. Although sexual function remained problematic, postoperative urinary function was good or fair in all ANP patients. In a retrospective analysis of 214 rectal cancer patients who underwent pelvic ANP, Sugihara et al. [24] evaluated oncologic outcome and urinary and male sexual function to classify four types of nerve-preservation procedures, for example unilateral pelvic plexus resection. They concluded that appropriate pelvic ANP should be applied with consideration of the balance between curability and QOL. It is therefore thought to be excessive to routinely perform extended lateral lymph node dissection with sacrifice of the autonomic nerves as a standard operation for rectal cancer, making precise preoperative assessment of the extent of local cancer spread important when determining the appropriate treatment strategy.

Surgical Treatment of Rectal Cancer
Prognostic Valuables in Patients with Lateral Lymph Node Metastases

Ueno et al. [26] examined the prognostic variables in rectal cancer patients with lateral lymph node metastases and showed that the most important factors determining prognosis are: distant metastasis; the total number of lymph nodes involved; circumferential resection margin, and age. They also confirmed that the histology in the submucosal invasive frontal region (tumor budding, poor differentiation, vascular invasion) reflects the extent of local spread [27]. Some reports have suggested limiting systemic lateral node dissection to patients with lateral lymph node metastases. Even after extended lateral lymph node dissection, the prognosis of patients with autonomic nerve plexus involvement was unfavorable [28]. Matsumoto et al. [29] also studied the feasibility of ANP surgery for advanced rectal cancer based on an analysis of micrometastases. In the study, patients with micrometastases to tissues surrounding the pelvic plexus had a poor outcome, even after extended dissection [29]. These results should encourage the use of adjuvant therapy for high-risk patients even after extended lymph node dissection.

\section{Other Modalities}

\section{Radiation Therapy for Local Control}

Radiation therapy of resectable rectal cancer has been widely accepted in the Western world. The use of radiation therapy reduces the risk of local recurrence and also 
controls subclinical disease in the regional lymph nodes. Combined TME and preoperative radiotherapy has become a very effective therapeutic concept in rectal cancer, resulting in a low local recurrence rate and improved survival $[30,31]$. In Japan, extended lateral lymph node dissection is a surgical procedure which resects macroscopic and microscopic local metastases. This procedure therefore has a potentially similar local control effect to adjuvant radiotherapy. Watanabe et al. [32] suggested that preoperative radiotherapy could be an alternative to extended lateral lymph node dissection. In the retrospective study, 115 rectal cancer patients were divided into two groups, and there was no difference between the group with radiotherapy (without lateral lymph node dissection) and the group with lateral lymph node dissection (without radiotherapy) in terms of recurrence rate and survival. A randomized controlled trial of lateral lymph node dissection versus nerve-preserving resection for rectal cancer after preoperative radiotherapy showed that there was no difference in the postoperative survival of patients who had systematic lateral dissection and those who did not [33]. This study also suggested that lateral node dissection is not necessary in terms of curability for patients with advanced rectal cancer who undergo preoperative radiotherapy. These studies suggested that the degree to which preoperative radiotherapy reduces the risk of recurrence is equivalent to that of lateral dissection, which can result in urinary and male sexual dysfunction.

\section{Adjuvant Chemotherapy for Systemic Control}

Despite the current quality of surgical procedures, locoregional treatment is limited as advanced primary rectal cancer may be associated with systemic spread of disease and distant metastases. The role of systemic adjuvant chemotherapy is therefore to obtain further improvement in survival. Although the role of systemic adjuvant chemotherapy in colon cancer patients with lymph node involvement has been established in a large number of clinical trials, rectal cancer differs from colon cancer in that there is an increased risk of local recurrence. The optimal adjuvant therapy for patients with rectal cancer has been combined systemic chemotherapy and radiotherapy, especially in the Western world. However, current practices of adjuvant therapy differ between countries and even between institutions within the same country. In Japan, several reports have demonstrated the usefulness of oral uracil-tegafur for adjuvant chemotherapy in colorectal cancer patients [34,35]. Since oral chemotherapeutic agents such as uracil-tegafur are advantageous due to their ease of administration, patient conve- nience and lack of need for catheterization, they have been widely used in Japan. Recently, adjuvant chemotherapy with uracil-tegafur was shown to improve survival of patients with stage III rectal cancer after standardized mesorectal excision with selective lateral lymph node dissection [36].

\section{Conclusion}

In the Japanese Guideline 2005 for Colorectal Cancer, the criteria for lateral lymph node dissection is lower-lying (below peritoneal reflection) and locally advanced $(>\mathrm{T} 2)$ rectal cancer. It is still unclear which procedure is superior, lateral lymph node dissection or TME. The randomized controlled trial of lateral lymph node dissection versus TME for rectal cancer of the Japan Clinical Oncology Group (JCOG0212 trial, http:/www.jcog.jp/) is currently underway, and the results are eagerly awaited. Retrospectively, both TME and lateral lymph node dissection for lower rectal cancer have achieved good local control, although the morbidity profiles are different. With the introduction of TME as a standardized, precise surgical technique, very low local recurrence rates have been reported by individual institutions $[4,8,9]$ and surgeon-related variability has been minimal. Havenga et al. [37] analyzed 691 patients with rectal cancer from three centers in the United States, Europe, and Japan and demonstrated similar survival and local recurrence rates in each. With today's standardized surgeon skill, low rates of local recurrence should be achieved with both TME and lateral lymph node dissection. However, there are limitations to these locoregional treatments, and adjuvant therapy is needed to prolong survival further. In addition, the individual preferences or medical conditions of the patient may play an important role in the choice of a particular treatment. For example, as the reduction in the rate of recurrence following lateral lymph node dissection is equivalent to that of radiotherapy, lateral dissection would be indicated in patients for whom radiotherapy is contraindicated.

By combining optimal surgical technique with appropriate surgical decision making, the surgeon can provide the patient with resectable rectal cancer the best chance of avoiding local recurrence, improved QOL, and ultimately, improved survival. In the future, molecular predictors of response to preoperative radiotherapy or sentinel lymph node mapping may facilitate further individualization, which will help to guide clinical decision making as well as identifying the best modality to use. 


\section{References}

1 Glimelius B, Isacsson U, Jung B, Pahlman L: Radiotherapy in addition to radical surgery in rectal cancer. Acta Oncol 1995;34:565-570.

2 Gastrointestinal Tumor Study Group: Adjuvant therapy of colon cancer: results of a prospectively randomized trial. N Engl Med 1984;310:737-743.

-3 Heald RJ, Husband EM, Ryall RD: The mesorectum in rectal cancer surgery - the clue to pelvic recurrence? Br J Surg 1982;69:613616.

-4 Heald RJ, Ryall RD: Recurrence and survival after total mesorectal excision for rectal cancer. Lancet 1986;i:1479-1482.

5 Miles WE: A method of performing abdomino-peritoneal excision for carcinoma of the rectum and of the terminal portion of the pelvic colon. Lancet 1908;ii:1812-1813.

-6 Williams NS, Durdey P, Johnston D: The outcome following sphincter-saving resection and abdominoperineal resection for low rectal cancer. Br J Surg 1985;72:595-598.

7 Pollett WG, Nicholls RJ: The relationship between the extent of distal clearance and survival and local recurrence rates after curative anterior resection for carcinoma of the rectum. Ann Surg 1983;198:159-163.

-8 MacFarlane JK, Ryall RD, Heald RJ: Mesorectal excision for rectal cancer. Lancet 1993; 341:457-60.

-9 Enker WE: Potency, cure, and local control in the operative treatment of rectal cancer. Arch Surg 1992;127:1396-1401.

$\checkmark 10$ Lowry AC, Simmang CL, Boulos P, Farmer KC, Finan PJ, Hyman N, Killingback M, Lubowski DZ, Moore R, Penfold C, Savoca P, Stitz R, Tjandra JJ: Consensus statement of definitions for anorectal physiology and rectal cancer: report of the Tripartite Consensus Conference on Definitions for Anorectal Physiology and Rectal Cancer, Washington, DC, May 1, 1999. Dis Colon Rectum 2001;44: 915-919.

-11 Morikawa E, Yasutomi M, Shindou K, Matsuda T, Mori N, Hida J, Kubo R, Kitaoka M, Nakamura M, Fujimoto K, et al: Distribution of metastatic lymph nodes in colorectal cancer by the modified clearing method. Dis Colon Rectum 1994;37:219-223.

-12 Hida J, Yasutomi M, Fujimoto K, Maruyama T, Okuno K, Shindo K: Does lateral lymph node dissection improve survival in rectal carcinoma? Examination of node metastases by the clearing method. J Am Coll Surg 1997; 184:475-480.

13 Yamakoshi H, Ike H, Oki S, Hara M, Shimada H: Metastasis of rectal cancer to lymph nodes and tissues around the autonomic nerves spared for urinary and sexual function. Dis Colon Rectum 1997;40:1079-1084.

14 Moriya Y, Sugihara K, Akasu T, Fujita S: Importance of extended lymphadenectomy with lateral node dissection for advanced lower rectal cancer. World J Surg 1997;21: 728-732.

-15 Takahashi T, Ueno M, Azekura K, Ohta H: Lateral node dissection and total mesorectal excision for rectal cancer. Dis Colon Rectum 2000;43:S59-S68.

16 Ueno M, Oya M, Azekura K, Yamaguchi T, Muto T: Incidence and prognostic significance of lateral lymph node metastasis in patients with advanced low rectal cancer. $\mathrm{Br} J$ Surg 2005;92:756-763.

17 Morita T, Murata A, Koyama M, Totsuka E, Sasaki M: Current status of autonomic nerve-preserving surgery for mid and lower rectal cancers: Japanese experience with lateral node dissection. Dis Colon Rectum 2003;46:S78-S87.

18 Fujita S, Yamamoto S, Akasu T, Moriya Y: Lateral pelvic lymph node dissection for advanced lower rectal cancer. Br J Surg 2003; 90:1580-1585.

19 Hojo K, Koyama Y, Moriya Y: Lymphatic spread and its prognostic value in patients with rectal cancer. Am J Surg 1982;144:350354.

20 Mori T, Takahashi K, Yasuno M: Radical resection with autonomic nerve preservation and lymph node dissection techniques in lower rectal cancer surgery and its results: the impact of lateral lymph node dissection. Langenbecks Arch Surg 1998;383:409-415.

21 Hojo K, Sawada T, Moriya Y: An analysis of survival and voiding, sexual function after wide iliopelvic lymphadenectomy in patients with carcinoma of the rectum, compared with conventional lymphadenectomy. Dis Colon Rectum 1989;32:128-133.

22 Fengler SA, Pearl RK: Technical considerations in the surgical treatment of colon and rectal cancer. Semin Surg Oncol 1994;10: 200-207.

23 Bruch HP, Schwandner O, Schiedeck TH, Roblick UJ: Actual standards and controversies on operative technique and lymph-node dissection in colorectal cancer. Langenbecks Arch Surg 1999;384:167-175.

24 Sugihara K, Moriya Y, Akasu T, Fujita S: Pelvic autonomic nerve preservation for patients with rectal carcinoma. Oncologic and functional outcome. Cancer 1996;78:18711880.

25 Maeda K, Maruta M, Utsumi T, Sato H, Toyama K, Matsuoka H: Bladder and male sexual functions after autonomic nervesparing TME with or without lateral node dissection for rectal cancer. Tech Coloproctol 2003;7:29-33.

26 Ueno H, Mochizuki H, Hashiguchi Y, Hase $\mathrm{K}$ : Prognostic determinants of patients with lateral nodal involvement by rectal cancer. Ann Surg 2001;234:190-197.

27 Ueno H, Mochizuki H, Shinto E, Hashiguchi Y, Hase K, Talbot IC: Histologic indices in biopsy specimens for estimating the probability of extended local spread in patients with rectal carcinoma. Cancer 2002;94: 2882-2891.

28 Ueno H, Mochizuki H, Fujimoto H, Hase K, Ichikura T: Autonomic nerve plexus involvement and prognosis in patients with rectal cancer. Br J Surg 2000;87:92-96.
-29 Matsumoto T, Ohue M, Sekimoto M, Yamamoto H, Ikeda M, Monden M: Feasibility of autonomic nerve-preserving surgery for advanced rectal cancer based on analysis of $\mathrm{mi}-$ crometastases. Br J Surg 2005;92:14441448.

30 Kapiteijn E, Marijnen CA, Nagtegaal ID, Putter H, Steup WH, Wiggers T, Rutten HJ, Pahlman L, Glimelius B, van Krieken JH, Leer JW, van de Velde CJ; Dutch Colorectal Cancer Group: Preoperative radiotherapy combined with total mesorectal excision for resectable rectal cancer. N Engl J Med 2001; 345:638-646.

31 Sauer R, Becker H, Hohenberger W, Rodel C, Wittekind C, Fietkau R, Martus P, Tschmelitsch J, Hager E, Hess CF, Karstens JH, Liersch T, Schmidberger H, Raab R; German Rectal Cancer Study Group: Preoperative versus postoperative chemoradiotherapy for rectal cancer. N Engl J Med 2004;351: 1731-1740.

32 Watanabe T, Tsurita G, Muto T, Sawada T, Sunouchi K, Higuchi Y, Komuro Y, Kanazawa T, Iijima T, Miyaki M, Nagawa H: Extended lymphadenectomy and preoperative radiotherapy for lower rectal cancers. Surgery 2002;132:27-33.

33 Nagawa H, Muto T, Sunouchi K, Higuchi Y, Tsurita G, Watanabe T, Sawada T: Randomized, controlled trial of lateral node dissection vs. nerve-preserving resection in patients with rectal cancer after preoperative radiotherapy. Dis Colon Rectum 2001;44: 1274-1280.

34 Kato T, Ohashi Y, Nakazato H, Koike A, Saji S, Suzuki H, Takagi H, Nimura Y, Hasumi A, Baba S, Manabe T, Maruta M, Miura K, Yamaguchi A: Efficacy of oral UFT as adjuvant chemotherapy to curative resection of colorectal cancer: multicenter prospective randomized trial. Langenbecks Arch Surg 2002;386:575-581.

35 Kusunoki M, Yanagi H, Kotera H, Noda M, Yamamura T: Effects of pharmacokinetic modulating chemotherapy using oral UFT and continuous venous 5FU infusion on the prognosis of irradiated rectal carcinomas with p53 overexpression. Int J Oncol 1998; 13:653-657.

36 Akasu T, Moriya Y, Ohashi Y, Yoshida S, Shirao K, Kodaira S; National Surgical Adjuvant Study of Colorectal Cancer: Adjuvant chemotherapy with uracil-tegafur for pathological stage III rectal cancer after mesorectal excision with selective lateral pelvic lymphadenectomy: a multicenter randomized controlled trial. Jpn J Clin Oncol 2006; 36:237-244.

37 Havenga K, Enker WE, Norstein J, Moriya Y, Heald RJ, van Houwelingen $\mathrm{HC}$, van de Velde CJ: Improved survival and local control after total mesorectal excision or D3 lymphadenectomy in the treatment of primary rectal cancer: an international analysis of 1,411 patients. Eur J Surg Oncol 1999;25:368374. 